\title{
Orientation and Order of Aqueous Organic Ions Adsorbed to a Solid Surface
}

\author{
Svetlana A. Sukhishvili and Steve Granick* \\ Department of Materials Science and Engineering, University of Illinois at Urbana-Champaign, \\ Urbana, Illinois 61801
}

Received: June 9, 1998; In Final Form: October 9, 1998

\begin{abstract}
The adsorption and orientation of an aqueous organic ion with anisotropic shape (1,4-dimethylpyridinium, $\mathrm{P}^{+}$) at the surface of oxidized silicon carrying opposite charge (produced by conditions of high $\mathrm{pH}$ ) were studied using polarized infrared spectroscopy in attenuated total reflection (FTIR-ATR). Orientation relative to the surface was quantified from the dichroic ratio of in-plane skeletal vibrations of the pyridinium ring (1643 and $1523 \mathrm{~cm}^{-1}$ ), and the adsorbed amount was inferred from the intensity of these bands. The sticking energy of the organic ion was slightly larger than that of small inorganic ions of the same charge $\left(\mathrm{Li}^{+}, \mathrm{Na}^{+}\right.$, $\left.\mathrm{Cs}^{+}\right)$. From relative quantities adsorbed in competitive adsorption, the relative sticking energy was quantified $\left(\sim 7 k_{\mathrm{B}} T\right.$ relative to $\mathrm{Na}^{+}$at $\mathrm{pH}=9.2$ and varying in the order $\mathrm{Cs}^{+}>\mathrm{Na}^{+}>\mathrm{Li}^{+}$by the total amount of $0.6 k_{\mathrm{B}} T$ ). At low ionic strength (no inorganic ions present except those in the buffer solution), $\mathrm{P}^{+}$stood preferably parallel to the surface when the surface coverage was low but more nearly upright both as its surface coverage increased and as the concentration of coadsorbed small ions increased. This shows the influence of steric packing on the orientation of this ion of asymmetric shape. The larger the hydrated diameter of the coadsorbed ion, the more the $\mathrm{P}^{+}$ion tilted away from the surface $\left(\mathrm{H}^{+}<\mathrm{Li}^{+}, \mathrm{Na}^{+}, \mathrm{Cs}^{+}<\mathrm{Mg}^{2+}\right)$. Furthermore, if the mass adsorbed exceeded a critical level, both the tilt and the amount adsorbed jumped in response to increasing $\mathrm{P}^{+}$concentration in bulk solution, with hysteresis upon dilution. This jump, together with the measured ellipsometric thickness and contact angle, suggests that the discontinuity involved structural change within a single monolayer. The organic ion thus behaved at the surface as an embryonic amphiphile, although in the bulk, micelle formation has not been reported.
\end{abstract}

\section{Introduction}

The most influential notions regarding ions at surfaces are still based on the classical "double layer" theories of GouyChapman and Debye-Hückel, ${ }^{1,2}$ which predict a charged element to be enveloped by a delocalized ion cloud of net opposite charge. These theories are based on the minimalist assumption that ions possess no volume or shape. Though most of the experiments confirm these notions for dilute solutions of simple small ions, ${ }^{1-4}$ recent ongoing discussion reveals the important complexities when correlations between ions are taken into account ${ }^{5,6}$ and also when both inorganic ions and water are modeled more realistically. ${ }^{7}$

Even for the smallest conceivable ion, the point-charge approximation should break down most prominently within the Stern layer, the molecularly thin layer of molecules closest to a solid surface. This complexity should, for several reasons, be most prominent for an organic ion. First, packing constraints originating from the asymmetric shape of such ions are prominent $^{8}$ these can result, for example, in overall undercompensation of surface charge even when the adsorbed amount reaches its maximum value. ${ }^{8}$ Second, the orientation of these adsorbed ions-hydrophilic at the charge moiety, hydrophobic at the organic moiety-should be also considered explicitly. Questions of this kind have been posed previously for surfactant ions at interfaces, ${ }^{9,10}$ where lateral interactions between the hydrocarbon tails determines guide orientational order at the interface. Here, we generalize the question to a much smaller

* Author to whom correspondence should be addressed. organic ion that would not form micelles in bulk solution. A preliminary account has appeared previously. ${ }^{11}$

The organic ion, the 1,4-dimethylpyridinium cation $\left(\mathrm{P}^{+}\right.$; molecular structure is drawn in the inset of Figure 1), was selected as the segmental analogue of a common water-soluble charged polymer, quaternized poly(1,4-vinylpyridine). A wide variety of other ions and polyions, ranging from anticoagulant or flocculation agents to polymer-based drugs, are also composed of charged organic units with amphiphilic character.

\section{Experimental Section}

Materials. The dimethylpyridinium ion $\left(\mathrm{P}^{+}\right)$was selected as the monomer analogue of alkylated poly(1,4-vinylpyridine). Crystals of 1,4-dimethylpyridinium iodide were obtained from Aldrich and purified by successive recrystallization via precipitation with ethanol until a clear color was obtained. Keeping in mind the vulnerability of $\mathrm{P}^{+}$ions to oxidation, experiments were performed soon after recrystallization with care to minimize exposure to light and atmospheric oxygen. The obtained crystals were vacuum-dried and kept under vacuum in dark-glass vials.

Experiments were performed at various $\mathrm{pH}$ values. To control the $\mathrm{pH}$ in the range from 8 to $11.5,3 \mathrm{mM}$ solutions of different mixtures of monobasic sodium phosphate, $\mathrm{NaH}_{2} \mathrm{PO}_{4} \cdot \mathrm{H}_{2} \mathrm{O}$, and dibasic sodium phosphate, $\mathrm{Na}_{2} \mathrm{HPO}_{4}$ (General Storage, pure grade), sodium borate, $\mathrm{Na}_{2} \mathrm{~B}_{4} \mathrm{O}_{7} \cdot 10 \mathrm{H}_{2} \mathrm{O}$, and sodium carbonate, $\mathrm{Na}_{2} \mathrm{CO}_{3}$ (Aldrich, purissima grade), with or without added $\mathrm{NaOH}$, were used. The inorganic salts $\mathrm{LiCl}, \mathrm{NaCl}$, and $\mathrm{CsCl}$ (General Storage, pure grade, or Aldrich, purissim grade) were used as received after control experiments showed no difference if they were baked first at $600{ }^{\circ} \mathrm{C}$. 

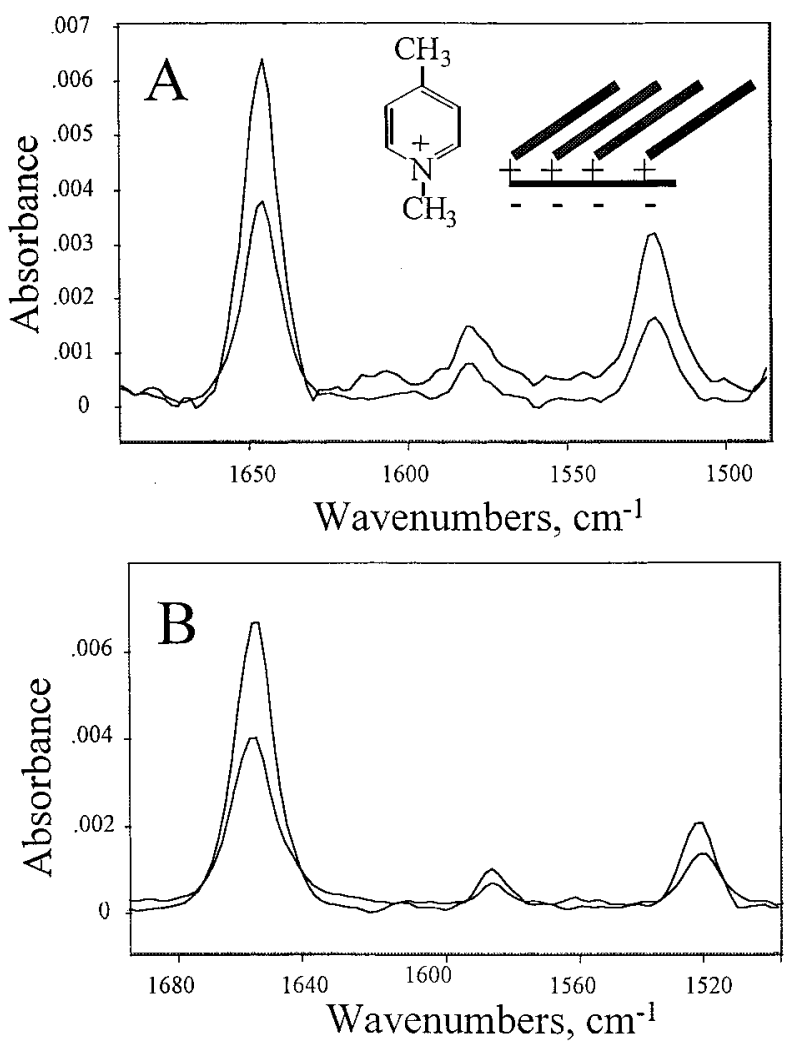

Figure 1. Representative infrared spectra of $\mathrm{P}^{+}$ions in $\mathrm{H}_{2} \mathrm{O}(\mathrm{A})$ and $\mathrm{D}_{2} \mathrm{O}$ (B) buffer solutions (1 mM Borax, $\mathrm{pH} 9.2$ and $\mathrm{pD} 9.4$, respectively). Concentration of $\mathrm{P}^{+}$is $10 \mathrm{mg} \mathrm{mL}^{-1}$. In each panel, the absorbance measured in both s- and p- polarizations (that taken in p-polarization is larger in magnitude) is plotted against wavenumber. These spectra contain contributions from the adsorbed and free $\mathrm{P}^{+}$, and the latter contribution was subtracted for the quantitative calculations presented in the succeeding figures. The inset in panel A shows the chemical structure of the $\mathrm{P}^{+}$ion and a cartoon of adsorbed $\mathrm{P}^{+}$.

The $\mathrm{H}_{2} \mathrm{O}$ was double-distilled and further purified by passage through a deionizing Milli-Q system (Millipore). To reduce overlap of the IR spectra of $\mathrm{P}^{+}$with those of water, we often used $99.9 \% \mathrm{D}_{2} \mathrm{O}$ (Sigma) rather than $\mathrm{H}_{2} \mathrm{O}$. The amount adsorbed was then $\sim 10 \%$ less at a given $\mathrm{pH}$ (this probably reflects isotopic influence on the dissociation constant of the surface silanol groups ${ }^{12}$ ), and raw spectra had slightly different peak ratios in $\mathrm{H}_{2} \mathrm{O}$ and $\mathrm{D}_{2} \mathrm{O}$ (as discussed below), but we verified that the main results did not depend on the choice of $\mathrm{H}_{2} \mathrm{O}$ or $\mathrm{D}_{2} \mathrm{O}$.

We studied adsorption at $25.0^{\circ} \mathrm{C}$ onto a flat, $45^{\circ}$ trapezoidal $50 \mathrm{~mm} \times 20 \mathrm{~mm} \times 2 \mathrm{~mm}$ silicon ATR crystal (Harrick Corp.) that had been treated as described previously. ${ }^{13}$ In brief, the silicon was rinsed with ethanol, cleaned in the UV-ozone chamber to lower surface contamination by hydrocarbons, then etched in 5\% hydrofluoric acid, and finally treated with ozone plasma. This procedure yields a smooth layer of the silanol groups on the crystal surface and lacks long-range order. ${ }^{13}$ Surface roughness of the prepared crystals was checked with profilometry and did not exceed $15 \AA$ normal to the surface.

At high $\mathrm{pH}$, the surface concentration of $\mathrm{SiO}^{-}$groups was assumed to be close to the value known to be characteristic of other silicates. ${ }^{14}$ This amounts to an average area of $0.2 \mathrm{~nm}^{2}$ per unit charge.

Data Acquisition. Measurements employed polarized FTIRATR (Fourier transform infrared spectroscopy in attenuated total reflection) using a Biorad FTS-60A spectrometer equipped with a mercury-cadmium-telluride detector and a home-built adsorption cell. ${ }^{15}$ When a wire-grid polarizer (Graesby/Specac) was switched, the spectra in $\mathrm{p}$ - and s-polarizations were obtained. Absorbance spectra were ratioed to the background spectra of aqueous or $\mathrm{D}_{2} \mathrm{O}$ buffer solutions containing the same concentration of inorganic salts as in the sample solution and measured in the same polarization. Details of the attenuated total reflection (ATR) measurements were reported elsewhere. ${ }^{15}$ Interferograms for both $\mathrm{p}$ - and s-polarizations were collected with $4 \mathrm{~cm}^{-1}$ resolution. The spectra were averaged for 512 or 1024 repeated scans.

Infrared Spectra. Figure 1 shows examples of the raw data obtained in $\mathrm{p}$ - and s-polarizations. The spectra refer to the iodide salt of $\mathrm{P}^{+}$dissolved at a concentration of $12 \mathrm{mg} \mathrm{mL}^{-1}$ in $\mathrm{H}_{2} \mathrm{O}$ and $\mathrm{D}_{2} \mathrm{O}$ buffer solutions (0.001 M Borax; $\mathrm{pH} 9.2$ and $\mathrm{pD} 9.4$, respectively). As follows from normal-mode analyses, the peaks in the region $1645-1400 \mathrm{~cm}^{-1}$ correspond to the in-plane (skeletal) vibration of the pyridinium ring. ${ }^{16,17}$ The band at 1643 $\mathrm{cm}^{-1}$ is characteristic of quaternized pyridinium rings; ${ }^{18}$ it appears in the spectra, in the course of quaternization of pyridine compounds, at the expense of the disappearance of the 1600 $\mathrm{cm}^{-1}$ band. We suppose that the transition moment associated with the $1643 \mathrm{~cm}^{-1}$ band is directed along $\mathrm{N}-\mathrm{C} 4$ line within a pyridinium ring. This direction is strongly supported by our experiments, although the direction perpendicular rather than parallel to the $\mathrm{N}-\mathrm{C} 4$ line has previously been reported by others. ${ }^{19}$ The peak at $1523 \mathrm{~cm}^{-1}$ is probably similar to the peak at $1518 \mathrm{~cm}^{-1}$ that we observe to appear in spectra after quaternization of previously uncharged poly(4-vinylpyridine) chains ${ }^{20}$ and is possibly also associated with coupled $\mathrm{C}-\mathrm{C}$ and $\mathrm{C}-\mathrm{N}^{+}$in-plane vibrations of the pyridinium ring. The latter assignment is supported by the normal-mode analysis performed for the closely located $1527 \mathrm{~cm}^{-1}$ vibration in the methyl viologen molecule. ${ }^{16}$ Simple trigonometric relations discussed below, based on the different dichroic ratios calculated for these two bands, show that the angle between the transition moments of these two in-ring vibrations was $32^{\circ}$.

The peaks were integrated by curve-fitting using Spectracalc software (Biorad). For this curve-fitting, the most consistent results were obtained when $90 \%$ of the peaks were assumed to be Gaussian and $10 \%$ to be Lorenzian. The peak centers and bandwidths were not fixed, but the results of the curve-fitting were carefully checked for consistency in these parameters.

Calibration of the Amount Adsorbed. Conversion of an integrated adsorption intensity into the mass adsorbed basically follows the method described elsewhere. ${ }^{21,22}$ It is based on integrating the amplitude of the evanescent wave and the concentration of the absorbing species as a function of distance from the crystal surface, yielding the integrated absorbance of the IR peaks. ${ }^{23,24}$ Assuming that the amplitude of the evanescent wave does not change within the thin layer of the adsorbed molecules, this integration gives the surface excess (the mass per unit area within the penetration depth of the evanescent wave that exceeds the expected amount from the known concentration in bulk solution):

$$
A=K\left(\Gamma+c_{\mathrm{s}} d_{\mathrm{p}} / 2\right]
$$

Here, $A$ denotes peak absorbance for nonpolarized radiation, $K$ is a constant, $\Gamma$ is the surface excess of the species at the interface, $c_{\mathrm{s}}$ is the bulk concentration of this species, and $d_{\mathrm{p}}$ is the penetration depth of the evanescent wave of the incident radiation. Provided that the intensities of parallel-polarized and perpendicular-polarized light are the same, we can further express the equation as 


$$
A=\left(A_{\mathrm{p}}+A_{\mathrm{s}}\right) / 2=\left(\left(K_{\mathrm{p}}+K_{\mathrm{s}}\right) / 2\right)\left(\Gamma+c_{\mathrm{s}} d_{\mathrm{p}} / 2\right)
$$

The calibration procedure includes determining the constants $K_{\mathrm{p}}$ and $K_{\mathrm{s}}$ in independent experiments in which absorbing species are brought in contact with a nonadsorbing surface. To produce a nonadsorbing surface, the silicon crystal was exposed for $2 \mathrm{~h}$ to a $\mathrm{P}^{+}$solution of relatively high concentration, $25 \mathrm{mg}$ $\mathrm{mL}^{-1}$, at $\mathrm{pH} 10.5$. After this, the solution was rapidly changed to yet higher concentrations ( $5 \mathrm{~min}$ at each concentration). The surface excess remained constant throughout this procedure such that changes in the integrated bands of $\mathrm{P}^{+}$stemmed from differences owing to the presence of $\mathrm{P}^{+}$in solution. Plotting absorbance in the $\mathrm{p}$ and $\mathrm{s}$ directions $\left(A_{\mathrm{p}}+A_{\mathrm{s}}\right)$ against solution concentration $\left(c_{\mathrm{s}}\right)$, this calibration gave slopes of 0.012 and $0.00425 \mathrm{AU} \mathrm{mL} \mathrm{mg} \mathrm{mg}^{-1}$ for the 1643 and $1523 \mathrm{~cm}^{-1}$ bands, respectively (AU denotes absorbance units). Using the expected penetration depth values of $0.471 \mu \mathrm{m}$ for the $1643 \mathrm{~cm}^{-1}$ band and $0.508 \mu \mathrm{m}$ for $1523 \mathrm{~cm}^{-1}$, we found the corresponding values of $\left(K_{\mathrm{p}}+K_{\mathrm{s}}\right): 0.0509$ and $0.0166 \mathrm{AU} \mathrm{m}^{2} \mathrm{mg}^{-1}$. These values were used throughout this work to calculate the surface excess of $\mathrm{P}^{+}$ions.

Whenever measurements were made in the presence of the solution species (always of known concentration), this calibrated solution contribution was first subtracted from the total measured absorbance. We note that changes in the solution concentration owing to adsorption were negligibly small; the maximum amount adsorbed was a fraction $10^{-3}-10^{-4}$ of the initial quantity in solution.

No difference of calibration was found when the salt concentration was varied. In particular, calibration curves were the same in the presence of $0.5 \mathrm{M} \mathrm{NaCl}$ as in buffer solution. This is expected because the difference of refractive index between pure water and aqueous $0.5 \mathrm{M} \mathrm{NaCl}$ is only $0.004825,{ }^{25}$ resulting in essentially the same penetration depth of infrared radiation in ATR experiments (differences of $2 \%$ were not experimentally distinguishable). The observed similarity showed also that molecular absorptivity of $\mathrm{P}^{+}$did not depend on salt concentration.

A complication, in the case of ionic adsorption, is that surface excess measured in an ATR experiment measures not only ions bound at the interface but also ions located within the diffuse part of the ionic double layer. The contribution of this ionic cloud depends on the surface potential and cannot be correctly taken into account in the calibration experiments described above. We investigated this matter by comparing the amount adsorbed, calculated by subtraction of the solution contribution in the manner just described (Figure 4, curve 1), with that measured after replacing the solution by water-lacking $\mathrm{P}^{+}$. No difference was observed within the experimental uncertainty of 5-10\%.

Comparison of Infrared Absorbance in $\mathrm{H}_{2} \mathrm{O}$ and $\mathrm{D}_{2} \mathrm{O}$. Neither intensity nor frequency of the ring in-plane vibration at $1643 \mathrm{~cm}^{-1}$ was affected by the isotopic substitution of the solvent; nearly the same calibration curves were obtained in $\mathrm{H}_{2} \mathrm{O}$ and $\mathrm{D}_{2} \mathrm{O}$. This was expected, since the penetration depth of an ATR evanescent wave and the absorptivity of the dissolved species depend on the refractive indices of the medium, ${ }^{23,26}$ which are nearly the same at $1643 \mathrm{~cm}^{-1}$ for $\mathrm{H}_{2} \mathrm{O}(n=1.32)$ as $\mathrm{D}_{2} \mathrm{O}(n=1.33) .{ }^{27,28}$ Distortion of the spectra owing to changes of the refractive index in water around $1640 \mathrm{~cm}^{-1}$, originating from overlap with strong $\mathrm{OH}$-bending water vibration bands, proved to have a negligible effect on the data because distortions canceled out when experimental spectra were ratioed to background spectra. The test of the validity of this point was to inspect the spectra for symmetry (distortions, which depend on wavenumber, tending to produce asymmetric line shape), but as Figure 1 shows, absorption bands in water were symmetric in shape.

However, the band at $1523 \mathrm{~cm}^{-1}$ was considerably weaker in $\mathrm{D}_{2} \mathrm{O}$ than in $\mathrm{H}_{2} \mathrm{O}$. Whereas in $\mathrm{H}_{2} \mathrm{O}$ it was a factor 3.0 weaker than the band at $1643 \mathrm{~cm}^{-1}$, in $\mathrm{D}_{2} \mathrm{O}$ this factor was 3.95 . It is not clear at this time why only this band was affected by the isotopic substitution of the solvent; however, different solvation properties of $\mathrm{D}_{2} \mathrm{O}$ and $\mathrm{H}_{2} \mathrm{O}$ have been reported. ${ }^{29}$

Dichroism Measurements. To infer orientation information from the infrared spectra, we used the dichroic ratio, $D$, defined as the ratio of absorptivities for $\mathrm{p}$ - and s- polarizations, $D \equiv$ $A_{\mathrm{p}} / A_{\mathrm{s}}$. For a model in which a transition moment of the vibration is only allowed to rotate freely within $X Y$ plane while keeping constant the angle $\phi$ with the surface normal,

$$
D \equiv A_{\mathrm{p}} / A_{\mathrm{s}}=\left(E_{x}^{2}+2 E_{z}^{2} \cot ^{2} \phi\right) / E_{y}^{2}
$$

where $E_{x}$ and $E_{y}$ are the amplitudes of the electric field at the interface lying in the plane of the crystal surface and $E_{z}$ is perpendicular to it. These amplitudes can be easily derived from the known angle of incidence of the IR beam and the known refractive indices of the crystal and the solvent. ${ }^{23}$ These values were found to be $E_{x}=1.39, E_{y}=1.5348$, and $E_{z}=1.66$. Here, $x$ and $y$ are Cartesian directions in the plane of the surface and $z$ is normal to it. For a random array of the molecules (or for the molecules aligned on the surface with a "magic angle" of $54.7^{\circ}$ to the surface normal),

$$
D=\left(E_{x}^{2}+E_{z}^{2}\right) / E_{y}^{2}
$$

which yields 2.05 for our case. Values of $D<2.05$ indicate alignment of the transition moment preferentially parallel to the surface $(D=0.82$ for perfectly parallel alignment), and $D>$ 2.05 indicates preferentially vertical orientation $(D \rightarrow \infty$ for a perfectly vertical array).

One complication, for the case when the refractive index of the thin layer of adsorbed molecules is different from that of the solvent, is that the $E_{z}$ component of the electric field should be corrected by the ratio of the refractive indices of the solvent and the adsorbed layer. ${ }^{23,32}$ If this mismatch were big enough, it would considerably affect the isotropic value of dichroic ratio. However, experimentally, we found $D=1.94$ for $\mathrm{P}^{+}$ions in solution. This is not much different from the calculated value of 2.05 and corresponds only to a 0.03 difference of refractive index between the adsorbed layer and the bulk solution; this small difference is consistent with the value obtained from in situ ellipsometry for adsorbed aqueous protein layers. ${ }^{33}$ Since this magnitude of refractive index mismatch would (if included in calculations) introduce only a $1^{\circ}$ correction to the calculated $\phi$ values, and keeping in mind recent criticism of this "thin layer approximation" as leading to physically unrealistic results, ${ }^{34}$ we ignored it in our calculations.

Note that though the above dichroism analysis is somewhat different from one previously used in the group, ${ }^{14}$ the two methods give only a $1-2^{\circ}$ discrepancy in the calculated angles.

To separate the dichroism of the adsorbed species $\left(D_{\mathrm{ads}}\right)$ from the total dichroism of both bound and solution $\mathrm{P}^{+}$ions $\left(D_{\Sigma}\right)$, we used the equation

$$
D_{\mathrm{ads}}=\left(D_{\Sigma} A_{\Sigma}-A_{\mathrm{sol}}\right) /\left(A_{\Sigma}-A_{\mathrm{sol}}\right)
$$

where $A_{\Sigma}$ is the total absorbance of both adsorbed and solution species and $A_{\text {sol }}$ is absorbance of solution species calculated from the calibration curve. The subtracted $A_{\text {sol }}$ did not exceed $40 \%$ 


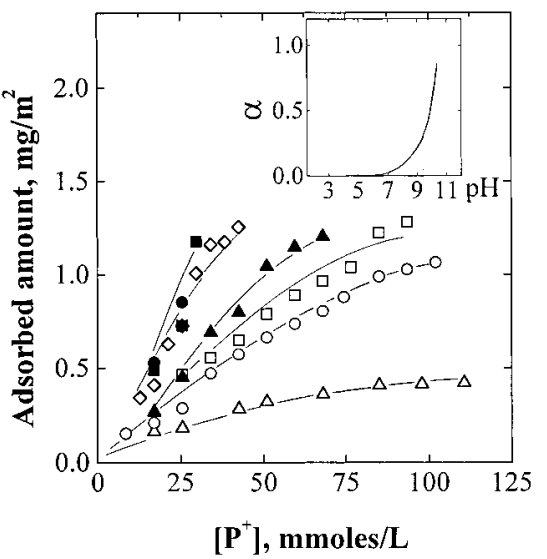

Figure 2. Dependence of adsorbed amount on solution concentration of the $\mathrm{P}^{+}$ion at $\mathrm{pH}=8.4$ (open triangles), 9.2 (open circles), 10.3 (open squares), 10.5 (solid triangles), 10.7 (open diamonds), 10.8 (solid squares), and 11.5 (solid circles). The following buffer solutions were used to control $\mathrm{pH}$ : $1 \mathrm{mM}$ phosphate at $\mathrm{pH}=8.4,1 \mathrm{mM}$ sodium borate at $\mathrm{pH}=9.2,1 \mathrm{mM}$ sodium carbonate at $\mathrm{pH}=10.8,1 \mathrm{mM}$ mixed borate and carbonate at $\mathrm{pH}$ from 9.2 to 10.8 , and a mixture of sodium carbonate and $\mathrm{NaOH}$ at $\mathrm{pH}=11.5$. The inset shows the $\mathrm{pH}$-dependent fraction of ionized surface silanol groups, $\alpha$, estimated from the known $\mathrm{p} K \approx 9.35$ for silanol groups. $^{35}$

of the total absorbance. In the case that adsorption was hysteretic upon dilution, the calculated values of the dichroism of adsorbed molecules were compared with those found experimentally; the two values were equal within an experimental uncertainty of $2-3 \%$.

\section{Results and Discussion}

pH Effect on the $\mathbf{P}^{+}$Ion Adsorption. Figure 2 summarizes the adsorption isotherms of $\mathrm{P}^{+}$ions onto the surface of oxidized silicon at several different values of high $\mathrm{pH}$. The graph shows only the region of the isotherm where the surface excess was less than $1.2 \mathrm{mg} \mathrm{m}^{-2}$. At $\mathrm{pH}=8.0$ the adsorbed amounts were low, as should be expected because ionization of the surface groups is not large (5-20\%), as can be calculated from reported $\mathrm{p} K$ values of silanol groups $\left(9.1-9.6^{35}\right)$. The higher adsorption at higher $\mathrm{pH}$ correlates with increasing surface charge density. We conclude that the adsorption of $\mathrm{P}^{+}$was predominantly driven by electrostatic attraction to the surface of opposite charge. However, adsorption of the polyelectrolyte analogue of $\mathrm{P}^{+}$, quaternized poly(4-vinylpyridine), has suggested an additional smaller contribution stemming from nonelectrostatic affinity to the surface of oxidized silicon. ${ }^{36} \mathrm{We}$ will discuss this later in connection with competitive adsorption of $\mathrm{P}^{+}$and small ions.

The significant point is that this dependence, for the monomeric analogue of the polyelectrolyte, is not linear. In contrast, for polyelectrolyte chains adsorbed to surfaces bearing ionizable groups, the surface excess has been found to grow linearly with increasing $\mathrm{pH} .{ }^{37}$ This difference points toward the influence of chain connectivity. In the case of a polyion, ionization of surface groups on a solid substrate (in this system, it would be silanol groups on the oxidized silicon) increases as chains adsorb; the mechanism appears to be cooperative formation of sequences of ionic contacts with the surface, ${ }^{38}$ with the result that additional polymer adsorbs to the surface. This charge regulation does not happen when nonpolymeric ions adsorb. In this case the amount of ions adsorbed correlates with the charge of a bare surface, which varies exponentially rather than linearly with changes in $\mathrm{pH}(\sigma \approx \sinh (\Delta(\mathrm{pH}) / 2))$.

Desorption experiments showed pronounced hysteresis: a negligible amount of $\mathrm{P}^{+}$desorbed when the solution concentra-

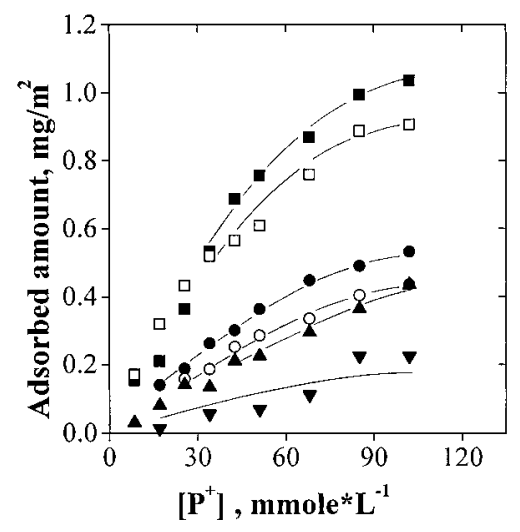

Figure 3. Dependence of adsorbed amount on solution concentration of the $\mathrm{P}^{+}$ion at different concentrations of sodium chloride added to the $1 \mathrm{mM}$ borate buffer: no added $\mathrm{NaCl}$ (squares), $0.03 \mathrm{M}$ (circles), $0.1 \mathrm{M}$ (up triangles), and $0.5 \mathrm{M}$ (down triangles). Filled symbols refer to experiments in $\mathrm{H}_{2} \mathrm{O}(\mathrm{pH}=9.2$ ), open symbols to experiments in $\mathrm{D}_{2} \mathrm{O}(\mathrm{pD}=9.4)$.

tion was lessened. Rinsing of the cell up to 10 times with pure buffer solution reduced the adsorbed amount by no more than $15 \%$. The traditional explanation for such hysteresis would be adsorption in pores. This is hardly applicable here, however; control experiments showed that increase of the ionic strength $(0.5 \mathrm{M} \mathrm{NaCl}$ added to the same buffer solution) displaced all the adsorbed $\mathrm{P}^{+}$. The reason for this hysteresis might be a lateral interaction between pyridinium rings, which may play a role even at this relatively low surface coverage.

Competitive Adsorption of $\mathbf{P}^{+}$and Small Ions. Figure 3 shows the adsorption isotherms of $\mathrm{P}^{+}$ions from saline solutions of different concentrations. Filled symbols refer to the experiments in $\mathrm{H}_{2} \mathrm{O}$, the open ones to experiments in $\mathrm{D}_{2} \mathrm{O}$; the mass adsorbed in the latter case was systematically $\sim 10 \%$ smaller for reasons discussed in the Experimental Section. One observes that the higher the $\mathrm{NaCl}$ concentration, the less the mass of $\mathrm{P}^{+}$ ions adsorbed. This suggests competition between $\mathrm{Na}^{+}$and $\mathrm{P}^{+}$ ions for the adsorption, which in principle may originate through screening of the attraction to the surface and competition for the adsorption sites. The data, however, could be satisfactorily described by the simplistic scheme of Langmuir-type adsorption of ions within a Stern layer. As follows from this analysis, the effective energy of the binding of $\mathrm{P}^{+}$ions is $\sim 7 k T$ in $0.001 \mathrm{M}$ buffer $(\mathrm{pH}=9.2)$; a similar value was reported by Denoyel et al. for the adsorption of $N, N, N$-trimethylaminoethyl chloride acrylate onto clay and silica surfaces. ${ }^{38}$ This value decreased to $\sim 3 k T$ in buffered $0.5 \mathrm{M} \mathrm{NaCl}$. The comparison based on the competitive scheme of Langmuir adsorption also showed that $\mathrm{Na}^{+}$and $\mathrm{P}^{+}$possess comparable affinity for the surface.

The importance of site specificity in determining adsorption showed up as a large dependence upon the type of inorganic ion. Figure 4 compares the adsorption isotherms of $0.1 \mathrm{M}$ solutions of $\mathrm{Li}^{+}, \mathrm{Na}^{+}$, and $\mathrm{Cs}^{+}$aqueous solutions at $\mathrm{pH}$ 9.2. One observes that the affinity of the cations for the surface decreased in the sequence $\mathrm{Cs}^{+}>\mathrm{Na}^{+}>\mathrm{Li}^{+}$, which is consistent with earlier reports for adsorption on silica and crystalline cellulose ${ }^{39-41}$ Incidentally, this sequence correlates well with the increasing hydration enthalpy and decreasing polarizability of these ions in this range. The effect suggests that competition of the inorganic and $\mathrm{P}^{+}$ions to a large degree occurred at the surface rather than in solution. From a comparison of these isotherms, we found the difference in the specific energy of adsorption between $\mathrm{Cs}^{+}$and $\mathrm{Li}^{+}$to be $0.6 \mathrm{kT}$.

Figure 4 shows also the effect of $\mathrm{MgCl}_{2}$ on the amount adsorbed. It is not surprising to find that to decrease the amount 


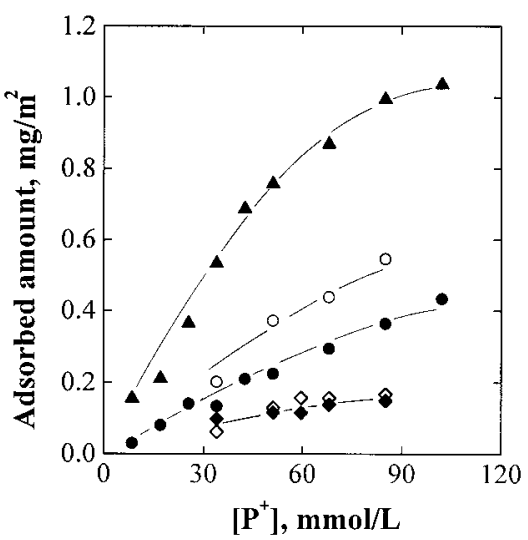

Figure 4. Dependence of the amount adsorbed on solution concentration of $\mathrm{P}^{+}$in the presence of various co-ions. The various inorganic ions are indicated as buffer only (triangles), $0.1 \mathrm{M} \mathrm{LiCl}$ (open circles), $0.1 \mathrm{M} \mathrm{NaCl}$ (filled circles), $0.1 \mathrm{M} \mathrm{CsCl}$ (open diamonds), and $0.01 \mathrm{M}$ $\mathrm{MgCl}_{2}$ (filled diamonds). The $\mathrm{pH}$ was 9.2.

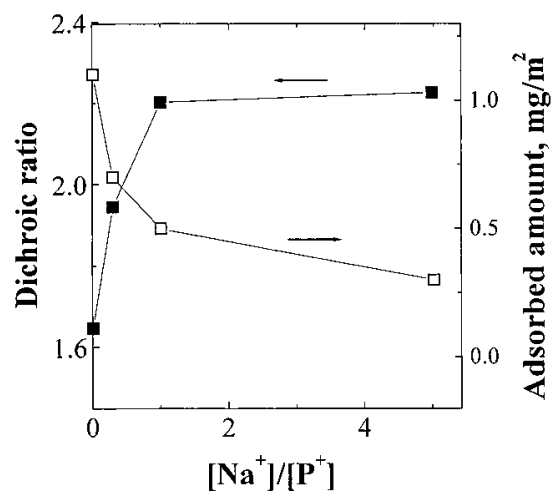

Figure 5. Dichroic ratio (open squares, left axis) of the carbonnitrogen stretch vibration at $1643 \mathrm{~cm}^{-1}$ of $\mathrm{P}^{+}$ions adsorbed from $\mathrm{D}_{2} \mathrm{O}$ onto oxidized silicon at $\mathrm{pH}=9.2$, and the amount adsorbed (filled squares, right axis) plotted against a molar ratio of $\mathrm{Na}^{+}$to $\mathrm{P}^{+}$ concentration in solution with $\left[\mathrm{P}^{+}\right]$fixed at $100 \mathrm{mM} \mathrm{L}^{-1}$.

of $\mathrm{P}^{+}$adsorbed to the same level, one requires a much lower ( $\sim 10$ times) concentration of $\mathrm{MgCl}_{2}$ than that of $\mathrm{NaCl}$. As follows from the previous discussion, this ratio reflects not only different electrostatic influences on the surface affinity but also nonelectrostatic ones.

Dichroism of the $\mathbf{P}^{+}$Adsorbed in Competition with Small Ions. We are specifically interested in orientation of the adsorbed $\mathrm{P}^{+}$ions with respect to the surface. The question arose, for example, of whether competition of $\mathrm{P}^{+}$and $\mathrm{Na}^{+}$ions for access to the surface would influence the orientation of adsorbed $\mathrm{P}^{+}$ ions. Figure 5 shows the dependence of $D$ (dichroic ratio) on the ratio of $\mathrm{Na}^{+}$to $\mathrm{P}^{+}$ions in solution (with a fixed concentration of $100 \mathrm{mmol} \mathrm{L}^{-1}$ of $\mathrm{P}^{+}$in solution). As long as the total salt concentration was low, $D$ was smaller than 2.05 , showing preferentially parallel orientation of pyridinium rings at the surface. With increasing salt concentration, the dichroic ratio rose monotonically, suggesting a more upright orientation of the adsorbed $\mathrm{P}^{+}$ions. A plateau was reached at the molar ratio $\left[\mathrm{Na}^{+}\right] /\left[\mathrm{P}^{+}\right] \approx 1$, which is consistent with our earlier conclusion (above) that the surface affinities of $\mathrm{Na}^{+}$and $\mathrm{P}^{+}$are comparable. This adsorption was reversible when the salt concentration was subsequently lowered. Within the whole range of $\mathrm{Na}^{+}$to $\mathrm{P}^{+}$ ratio, the less $\mathrm{P}^{+}$adsorbed, the higher the $\mathrm{Na}^{+}$concentration, as already discussed above.

We postulate a simple geometrical picture for this competitive effect owing to coadsorption. The methyl group in this organic ion, which is attached to the nitrogen, creates a barrier to vertical

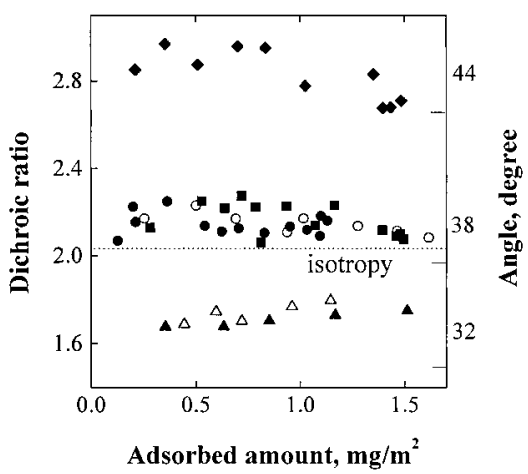

Figure 6. (Left axis) Dichroic ratio (carbon-nitrogen stretch vibration at $1643 \mathrm{~cm}^{-1}$ ) of dimethylpyridinium $\left(\mathrm{P}^{+}\right)$ions adsorbed from $\mathrm{D}_{2} \mathrm{O}$ onto oxidized silicon plotted against quantity adsorbed. The inorganic ion also in solution was varied: buffer alone (triangles), $0.1 \mathrm{M} \mathrm{LiCl}$ (open circles), $0.1 \mathrm{M} \mathrm{CsCl}$ (squares), $0.1 \mathrm{M} \mathrm{NaCl}$ (filled circles), and $0.01 \mathrm{M} \mathrm{MgCl}_{2}$ (diamonds). The $\mathrm{pH}$ was 10.8 . (Right axis) Tilt angle implied by the dichroic ratio was estimated with the assumptions of azimuthal symmetry and no angular distribution. Isotropy is indicated by the dotted line.

orientation of the ion on the surface. At low salt concentrations, the $\mathrm{P}^{+}$ring then sits preferentially parallel to the surface to minimize the distance between the positive charge of the molecule and the negative charge on the surface. The $\mathrm{P}^{+}$ion is roughly $3 \AA \times 8 \AA \times 9 \AA$ in dimension, as gauged from the crystalline structure of the salt form of the ion ${ }^{42}$ (though these numbers can be expected to increase slightly with hydration). It is conceivable that under low salt conditions each pyridinium ring occupied more than a single adsorption site and that the smaller ions, to gain access to these occluded adsorption sites, forced the observed orientation of $\mathrm{P}^{+}$.

The hypothesis indicated that the surface tilt of $\mathrm{P}^{+}$ions stemmed from the presence at the surface of inorganic ions with the same charge; these ions would be invisible in the IR experiment yet would affect orientation of the adsorbed $\mathrm{P}^{+}$ through geometrical constraints. To test the idea, we varied the size of inorganic co-ion. Figure 6 shows the dichroic ratio plotted against the surface coverage of $\mathrm{P}^{+}$. For buffer solutions used to control $\mathrm{pH}$ ("low salt") one observes the preferentially parallel alignment also seen in Figure 5. For several monovalent cations with nearly the same hydrated radius in water $(3.8,3.6$, and $3.3 \AA$ for $\mathrm{Li}^{+}, \mathrm{Na}^{+}$, and $\mathrm{Cs}^{+}$, respectively, ${ }^{1}$ the dichroic ratio of $\mathrm{P}^{+}$was $D \approx 2.2$. But the hydrated radius of $\mathrm{Mg}^{2+}$ is larger, $4.3 \AA{ }^{1}$ and we expect its size in solution to be further augmented at high $\mathrm{pH}$ by partial hydrolysis, so perhaps it is not surprising to observe a larger dichroic ratio, the observed $D \approx 2.9$. Although $D$ in this experiment was also influenced in principle by the roughness of the polished Si crystal (see Experimental Section), it was meaningful to compare relative values of $D$. It was not reasonable to make a quantitative correlation between the magnitude of the measured effect and the ionic sizes, since the hydrated radii of inorganic ions when they reside at a surface of opposite charge are not known, but the qualitative effect is unmistakable.

Control experiments showed the effect to be general. The dichroic ratio (therefore the surface tilt) did not change when the $\mathrm{pH}$ was varied by several $\mathrm{pH}$ units, as shown in Figure 7. Between $\mathrm{pH} 8.0$ and 10.5 one expects the surface charge to change by a factor of $\sim 10,{ }^{43}$ yet the dichroic ratio of the pyridinium rings proved to be nearly constant.

In all the experiments described above the amount of $\mathrm{P}^{+}$ions adsorbed did not exceed $1.2 \mathrm{mg} \mathrm{m}^{-2}$. At higher coverage, the adsorption then became cooperative and suggested a structural 


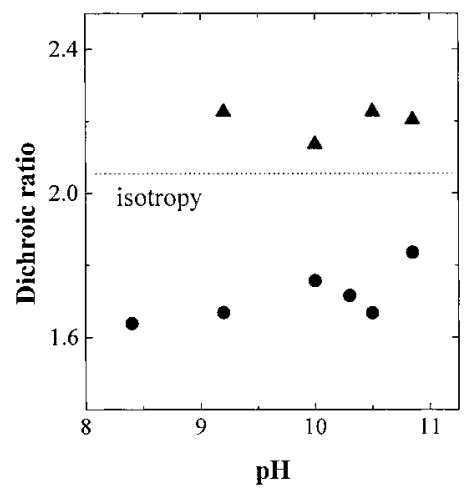

Figure 7. Dichroic ratio (carbon-nitrogen stretch vibration at 1643 $\mathrm{cm}^{-1}$ ) of dimethylpyridinium $\left(\mathrm{P}^{+}\right)$ions adsorbed from $\mathrm{D}_{2} \mathrm{O}$ onto oxidized silicon plotted against $\mathrm{pH}$. Filled circles indicate adsorption from buffer solution without additionally added salt $\left(2 \mathrm{mM} \mathrm{Na}^{+}\right)$. Filled triangles indicate adsorption from $0.1 \mathrm{M} \mathrm{NaCl}$ solution. The following buffer solutions used to control $\mathrm{pH}$ : $1 \mathrm{mM}$ sodium phosphate at $\mathrm{pH}=$ $8.4,1 \mathrm{mM}$ sodium borate at $\mathrm{pH}=9.2,1 \mathrm{mM}$ sodium carbonate at $\mathrm{pH}$ $10.8,1 \mathrm{mM}$ mixed borate and carbonate at the other $\mathrm{pH}$. Filled circles indicate adsorption from buffer solution without additionally added salt $\left(2 \mathrm{mM} \mathrm{Na}^{+}\right)$. Filled triangles indicate adsorption from $0.1 \mathrm{M} \mathrm{NaCl}$ solution. The adsorbed amount was $0.8 \mathrm{mg} \mathrm{m}^{-2}$ except at $\mathrm{pH}=8.4$, where it was $0.6 \mathrm{mg} \mathrm{m}^{-2}$. Isotropy is indicated by the dotted line.

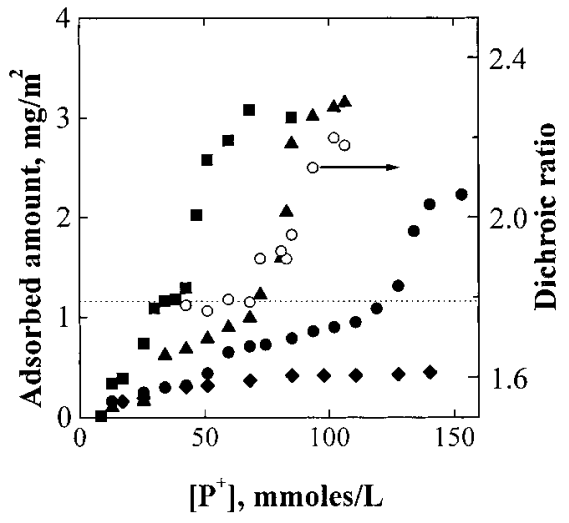

Figure 8. Adsorbed amount of $\mathrm{P}^{+}$(left axis) and dichroism of the carbon-nitrogen stretch vibration at $1643 \mathrm{~cm}^{-1}$ (right axis, open circles) plotted against $\mathrm{P}^{+}$molar concentration in $\mathrm{H}_{2} \mathrm{O}$. Adsorption was at $\mathrm{pH}$ $=11.5$ (squares), $\mathrm{pH}=10.5$ (triangles), $\mathrm{pH}=9.2$ (filled circles), and $\mathrm{pH}=8.0$ (diamonds). Except at $\mathrm{pH}=11.5$, where a mixture of sodium carbonate and $\mathrm{NaOH}$ was used, $\mathrm{pH}$ was regulated by buffer conditions described in the caption of Figure 2. No salt was added beyond the small amount required to establish buffer conditions $\left(2 \mathrm{mM} \mathrm{Na}{ }^{+}\right)$. Below the step the adsorption was rapid and reversible, but above the step it was slow to equilibrate. It was technically unfeasible to wait longer than $30 \mathrm{~min}$ for equilibration at each data point. The dotted line indicates the surface coverage at the adsorption step, $1.2 \mathrm{mg} \mathrm{m}^{-2}$.

transition within the monolayer at high surface coverage. This is described in the following sections.

Adsorption of $\mathbf{P}^{+}$. Structural Transition. Higher surface coverage than we have discussed so far could be achieved only in low-salt conditions (buffer solution alone) and at higher concentrations of $\mathrm{P}^{+}$than discussed till present. Figure 8 shows the surface excess of the $\mathrm{P}^{+}$ion plotted against its concentration (which was varied over a wide range) at different values of $\mathrm{pH}$. A striking feature of the isotherms is a rounded step after the amount of $\mathrm{P}^{+}$reached $1.2 \mathrm{mg} \mathrm{m}^{-2}$. The isotherms, at lesser surface coverage, agree with those in Figure 2. As also shown in Figure 8, the dichroism of the adsorbed $\mathrm{P}^{+}$ions also increased abruptly in the region of the step; the $\mathrm{P}^{+}$molecules tilted further away from the surface to accommodate larger amounts of the adsorbent. The same values of $D$, plotted against surface coverage of $\mathrm{P}^{+}$, make a continuously rising curve as shown in

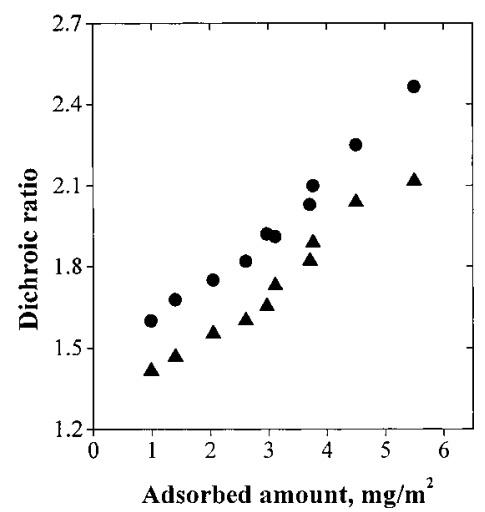

Figure 9. Dichroic ratio (carbon-nitrogen stretch vibration at 1643 $\mathrm{cm}^{-1}$ ) of dimethylpyridinium $\left(\mathrm{P}^{+}\right)$ions adsorbed from $\mathrm{D}_{2} \mathrm{O}$ onto oxidized silicon plotted against quantity adsorbed, as calculated from different adsorption bands of $\mathrm{P}^{+}$ion: $1643 \mathrm{~cm}^{-1}$ (circles) and 1523 $\mathrm{cm}^{-1}$ (triangles). The adsorption was measured in $1 \mathrm{mM}$ buffer solution at $\mathrm{pH} 10.8$.

Figure 9. One observes that the dichroism values calculated from infrared bands at 1643 and $1523 \mathrm{~cm}^{-1}$ followed the same tendency, though the $1523 \mathrm{~cm}^{-1}$ band consistently gave smaller numbers. This difference was used to estimate the in-ring direction of the transition moments for $1523 \mathrm{~cm}^{-1}$ (see Experimental Section). The dichroic ratio shown in Figure 8 is very similar to the initial part of the plot shown in Figure 5. This is expected, since the molecular mechanisms for the two phenomena are indeed similar; coadsorbed $\mathrm{P}^{+}$(Figure 8 ) or $\mathrm{Na}^{+}$ (Figure 5) had a similarly restrictive effect on the orientation of pyridinium ions within the adsorbed layer.

The surface coverage of $\mathrm{P}^{+}$at the point of the step, $1.2 \mathrm{mg}$ $\mathrm{m}^{-2}$, corresponds to a projected area of $33 \AA^{2}$ molecule ${ }^{-1}$. Though this number cannot be interpreted literally because of residual surface roughness despite polishing (see comments on roughness in the Experimental Section), it is similar in magnitude and slightly larger than the mean area of $20-25 \AA^{2}$ expected for $\mathrm{Si}-\mathrm{O}^{-}$groups on silica, as well as the molecular area of $25 \AA^{2}$ expected from the crystal structure. Hence, the negative surface charge might not be fully compensated at the point of the step, thus allowing more $\mathrm{P}^{+}$ions to adsorb.

Several facts suggest that the steep rise of the amount of $\mathrm{P}^{+}$ adsorbed represented a structural transition within a single adsorbed layer.

First, the kinetic features of adsorption were prominently different on both sides of the step in the isotherm. Figure 10 shows the kinetics of the adsorption of $\mathrm{P}^{+}$ions for these two regions. For surface excess less than $1.2 \mathrm{mg} \mathrm{m}^{-2}$, adsorption was immediate on the scale of minutes (curve 1 in Figure 10), presumably rate-determined by diffusion to the surface. But a much slower process, still not quite completed after $4 \mathrm{~h}$, set in after the step. We assume that slow kinetics in the latter case stemmed from slow intercalation of $\mathrm{P}^{+}$molecules within the layer of already rather closely packed molecules. Note that in the experiment shown in Figure 8 successive increases in solution concentration of $\mathrm{P}^{+}$were used, with equilibration times of 10-15 min per point. The slow kinetics might decrease the slope of the isotherm immediately after the step point, where experimental times were so much shorter than the $4 \mathrm{~h}$ equilibration for the process shown in Figure 10. For the latter reason, we do not interpret the rounded slope of the isotherms at high surface coverage.

A second significant argument concerns the different responses of the adsorbed $\mathrm{P}^{+}$ions to dilution in these two regions. In neither region did the surface-adsorbed $\mathrm{P}^{+}$ions desorb into 


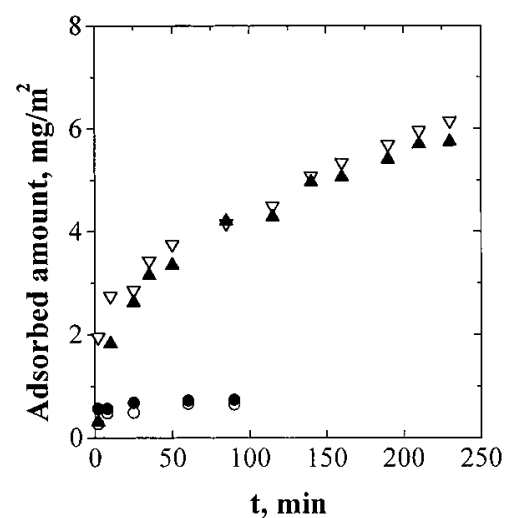

Figure 10. Kinetics of the adsorption of $\mathrm{P}^{+}$ions from water onto the surface of oxidized silicon at two different bulk concentrations of $\mathrm{P}^{+}$: $42 \mathrm{mM} \mathrm{L}^{-1}$ (circles) and $110 \mathrm{mM} \mathrm{L}^{-1}$ (triangles). The $\mathrm{pH}$ was 10.5 . Figure 8 illustrates that these two concentrations of $\mathrm{P}^{+}$lay in the prestep and poststep regions of the adsorption isotherm. Filled triangles indicate the amount adsorbed calculated from the infrared band at $1643 \mathrm{~cm}^{-1}$, the open triangles from the band at $1523 \mathrm{~cm}^{-1}$.

buffer of low ionic strength. This was also discussed above for the region before the step; it is expected also to hold in the after-step region, where lateral interactions between adsorbed $\mathrm{P}^{+}$molecules are stronger. However, a buffer of high ionic strength (with $0.5 \mathrm{M} \mathrm{NaCl}$ ) quickly and completely displaced adsorbed $\mathrm{P}^{+}$ions in the prestep region but had no effect at higher surface excess. This difference is easy to rationalize; at the lesser surface coverage, the $\mathrm{Na}^{+}$ions coadsorbed and successfully competed with $\mathrm{P}^{+}$ions for surface binding, whereas denser packing of these layers at higher coverage prevented $\mathrm{Na}^{+}$ions from access to the surface.

Third, these denser-packed films were significantly more hydrophobic than those at lesser surface coverage: the contact angle with water, $5-7^{\circ}$ for low surface coverage, jumped to $24^{\circ}$ above the adsorption step, consistent with a monolayer surface terminated with methyl groups.

Finally, ellipsometric measurements also revealed this step in the adsorption isotherms. The measurements were performed on pieces of $\mathrm{Si}$ wafer that were treated before the adsorption experiment using the same procedure as for Si crystals. First, $\mathrm{P}^{+}$ions were allowed to adsorb onto a certain Si piece for $4 \mathrm{~h}$. Then this wafer was carefully taken out of the solution, rinsed by careful dipping in buffer, and dried under weak nitrogen flow. Note that in this case severe shaking of the sample would remove the $\mathrm{P}^{+}$adsorbed film, but not gentle shaking. Figure 11 shows (after gentle shaking) a significant increase in the ellipsometric thickness to $9 \AA$ after the solution concentration exceeded $60-90 \mathrm{mmol} \mathrm{L}^{-1}$, a thickness that is inconsistent with multilayer formation. This is consistent with the IR data obtained for the same $\mathrm{pH}$ of 10.5, which were shown in Figure 8.

It is appropriate to consider alternative explanations for the observed step. One might suspect condensation of $\mathrm{P}^{+}$with negative charges on the surface. Ion condensation to maintain spacing between surface charges no smaller than the Bjerrum length has been much discussed. ${ }^{44}$ This line of argument would suggest that the surface charge density rose before the step because of the ionic strength increase (higher $\mathrm{P}^{+}$concentration in solution). The charge density of ionizable groups is known to vary with ionic strength. ${ }^{43} \mathrm{~A}$ definite resolution of this point would require an independent measure of surface charge, and this we could not measure with the equipment at our disposal.

Stepped isotherms have been also found previously for the adsorption of the surfactants. Here, the position of the kink is correlated with the $\mathrm{cmc}$ (critical micelle concentration of a

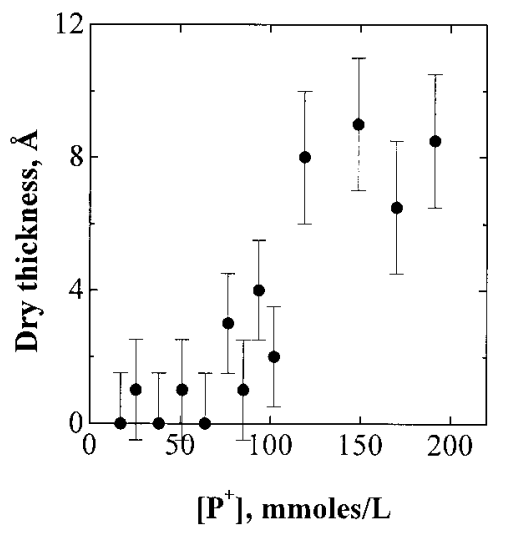

Figure 11. Ellipsometric thickness of dry layers of adsorbed $\mathrm{P}^{+}$ (measured using a Gaertner model L116C ellipsometer) plotted against $\mathrm{P}^{+}$molar concentration in buffered $\mathrm{H}_{2} \mathrm{O}$ at $\mathrm{pH}=10.5$ during adsorption. The formation of bilayers is unlikely in view of the limiting thickness of 7-10 $\AA$, which corresponds to a layer one molecule thick. The relatively hydrophobic surface after the adsorption step, with a contact angle $\theta=24^{\circ}$, also supports monolayer interpretation.

surfactant. ${ }^{10,45-47}$ This case is quite different from our experiments, where the position of the step depends on $\mathrm{pH}$ rather than solution concentration. Though self-assembly of the surfactants at the surface can happen at concentrations below the bulk $\mathrm{cmc}^{48}$ (and this in turn could depend on the surface charge and, hence, on the $\mathrm{pH}$ ), note that no $\mathrm{cmc}$ concentration has been reported for the $\mathrm{P}^{+}$molecule in the bulk. It is possible, however, that lateral interactions between adjacent $\mathrm{P}^{+}$ions promoted the ordering, especially since the solid substrate itself lacked longrange order. An energetic advantage to stacking of aromatic rings is known. ${ }^{49}$

One might also suspect bilayers or multilayers, since the presence of a step in an isotherm sometimes does indicate the formation of multilayers. ${ }^{50}$ This we carefully explored, but considered unlikely, for several reasons: first, because of the continuous rise of dichroism in the region of the step; second, because of the small ellipsometric thickness measured after the kink; finally, because of the hydrophobicity of the adsorbed $\mathrm{P}^{+}$ layers (bilayer formation would have produced a hydrophilic surface).

Surface-induced order in the otherwise isotropic liquid has also been observed in alkanes near the freezing temperature ${ }^{51}$ and in liquid crystals near the isotropic-ordering transition temperature. ${ }^{52}$ The influence of packing on the surface orientation of uncharged pyridinium rings was also recently hypothesized on the basis of observed steplike changes of the adsorption isotherm. ${ }^{53}$ For this uncharged molecule, a possible origin in terms of attractions between the aromatic rings was suggested. In our case, a charged molecule, packing may be further guided and locked in place by electrostatic attraction to the surface of opposite charge.

\section{Conclusions}

It is remarkable to find cooperative surface self-assembly of this charged organic ion for which no micelle concentration has been reported.

The observed influence of coadsorbed small inorganic ions on the orientation of the larger organic ion furthermore suggests a method by which an organic ion could be used to control the occluded area on an underlying surface, for example, the access to ion channels through a lipid membrane, by switching the concentration of inorganic ions in solution.

The relevance to polyelectrolyte adsorption is simple and, we suggest, far-reaching. If ions similar to $\mathrm{P}^{+}$are incorporated 
into a polymer as pendant side groups (as, for example, in quaternized poly(vinylpyridine)), obviously packing cannot be the same. One strong confounding influence will be stereoregularity of the polyelectrolyte chain; the permissible orientational order will be largest when the polymer is stereoregular and least when chiral sequences along the polymer backbone are random. Our experiments, similar to those reported in this paper in which polyelectrolytes of variable tacticity were studied (unpublished), confirm this expectation. This frustration suggests a new contribution to surface energetics when polyelectrolyte adsorbs.

The tendency of small organic ions to order at a disordered surface in aqueous solution may have ramifications in areas from electrochemistry to biochemistry.

Acknowledgment. This work was supported by the National Science Foundation and the Department of Energy.

\section{References and Notes}

(1) Israelachvili, J. N. Intermolecular and Surface Forces, 2nd ed.; Academic Press: New York, 1991.

(2) Lyklema, H. Fundamentals of Interface and Colloid Science; Academic Press: New York, 1991.

(3) Larsen A. E.; Grier, D. G. Nature 1997, 385, 230.

(4) Bedzyk, M. J.; Bommarito, G. M.; Gaffrey, M.; Penner, T. L. Science 1990, 248, 52.

(5) Carnie, S. L.; Torrie, G. M. Adv. Chem. Phys. 1984, 56, 141.

(6) Guldbrand, L.; Jonsson, B.; Wennerstrom, H.; Linse, P. J. Chem. Phys. 1984, 80, 2221.

(7) For example, see the following. Kjellander, R.; Marcelja, S. $J$. Chem. Phys. 1988, 88, 7138. Xia, X.; Berkowitz, M. L. Phys. Rev. Lett. 1995, 74, 3193. Danielewicz-Ferchmin, I.; Ferchmin, A. R. J. Phys. Chem. 1996, 100, 17281.

(8) Claesson, P.; Horn, R. G.; Pashley, R. M. J. Colloid Interface Sci. $1990,100,250$

(9) Kung, K.-H. S.; Hayes, K. F. Langmuir 1993, 9, 263.

(10) Tiberg, F.; Jonsson, B.; Tang, Ji-an; Lindman, B. Langmuir 1994, $10,2294$.

(11) Sukhishvili, S. A.; Granick, S. Phys. Rev. Lett. 1998, 80, 3646.

(12) Glaose, P. K.; Long, F. A. J. Phys. Chem. 1960, 64, 188

(13) Frantz, P.; Granick, S. Langmuir 1995, 8, 1176.

(14) Iler, R. K. Chemistry of Silica; Wiley: New York, 1979.

(15) Frantz, P.; Granick, S. Macromolecules 1995, 28, 6915.

(16) Hester, R. E.; Suzuki, S. J. Phys. Chem. 1982, 86, 4626.

(17) Ghoshal, S.; Lu, T.; Feng, Q.; Cotton, T. M. Spectrochim. Acta 1988, $44 A(7), 651$.

(18) Itoh, K. I.; Yamamoto, M.; Wajima, T. J. Mol. Struct. 1993, 293, 311.

(19) Tang, X.; Schneider, Th.; Buttry, D. A. Langmuir 1994, 10, 2235.
(20) Sukhishvili, S.; Granick, S. Langmuir 1997, 13, 4935.

(21) Sperline, R. P.; Muralidharan, S.; Freiser, H. Langmuir 1987, 3 , 198.

(22) Azzorardi, M. J.; Arribat, H. J. Adhes. 1994, 46, 103.

(23) Harrick, N. J. J. Opt. Soc. Am. 1965, 55, 851.

(24) Tompkins, H. G. Appl. Spectrosc. 1974, 28, 335.

(25) Huglin, M. H. In Polymer Handbook, 3rd ed; Brandrup, J., Immergut, E. H., Eds.; Wiley: New York, 1989.

(26) Dack, M. R. J., Ed. Solutions and Solubilities; John Wiley \& Sons: New York, 1975.

(27) Pinkley, L. W.; Sethna, P. P.; Williams, D. J. Opt. Soc. Am. 1977, 67 (4), 494.

(28) Sethna, P. P.; Palmer, K. F.; Williams, D. J. Opt. Soc. Am. 1978, 68 (6), 815

(29) Bonnete, F.; Zaccai, G. Biophys. Chem. 1994, 53, 69

(30) Frey, S.; Tamm, L. K. Biophys. J. 1990, 60, 922.

(31) Sperline, R. P.; Song, Y.; Freiser, H. Langmuir 1992, 8 (9), 2183

(32) Haller, G. L.; Rice, R. W. J. Phys. Chem. 1970, 74 (25), 4386.

(33) Malmsten, M. J. Colloid Interface Sci. 1994, 166, 333.

(34) Citra, M. J.; Axelsen, P. H. Biophys. J. 1996, 71, 1796.

(35) Perrin, D. D. Ionisation contstants of inorganic acids and bases in aqueous solution; Pergamon Press: Oxford, 1982; p 99.

(36) Hoogeveen, N. G.; Cohen Stuart, M. A.; Fleer, G. J. J. Colloid Interface Sci. 1996, 182, 133.

(37) Sukhishvili, S. A.; Chechik, O. S.; Yaroslavov, A. A. J. Colloid Interface Sci. 1996, 178, 281.

(38) Denoyel, R.; Durand, G.; Lafuma, F.; Audebert, R. J. Colloid Interface Sci. 1990, 139, 281 .

(39) Tadros, Th. F.; Lyklema, J. J. Electroanal. Chem. 1968, 17, 267.

(40) Kondo, S.; Tamaki, T.; Ozeki, Y. Langmuir 1987, 3, 349.

(41) van de Steeg, H. G. M.; de Keizer, A.; Cohen Stuart, M. A.; Bijsterbosch, B. H. Colloids Surf. A 1993, 70, 77.

(42) Narula, S. P.; Kaur, S.; Sharma, S. K.; Povey, D. C. J. Crystallogr. Spectrosc. Res. 1992, 22, 139.

(43) Kokufuta, E.; Fujii, S.; Hirai, Y.; Nakamura, I. Polymer 1982, 23, 452.

(44) Manning, G. S. Q. Rev. Biophys. 1978, 2, 179.

(45) Conner, P.; Ottewill, R. H. J. Colloid Interface Sci. 1971, 37, 642.

(46) Scamehorn, J. F.; Schechter, R. S.; Wade, W. H. J. Colloid Interface Sci. 1982, 85, 463.

(47) Herder, P. C.; Claesson, P. M.; Herder, C. E. J. Colloid Interface Sci. 1987, 119, 155.

(48) Ligoure, C. Macromolecules 1991, 24, 2968.

(49) Vögtle, F. Supermolecular Chemistry; John Wiley \& Sons: New York, 1991

(50) Sexton, B. A.; Mitchell, G. E. Surf. Sci. 1980, 99, 539.

(51) Tkachenko, Av.; Rabin, Y. Phys. Rev. E 1997, 55, 778 and references therein.

(52) Lucht, R.; Bahr, Ch. Phys. Rev. Lett. 1997, 78, 3487 and references therein.

(53) Sellami, H.; Hamraoui, A.; Privat, M.; Olier, R. Langmuir 1998 14, 2402. 